\title{
Does insurance demand react to economic policy uncertainty and geopolitical risk? Evidence from Saudi Arabia
}

\author{
Wael Hemrit ${ }^{1,2}$ (D) \\ Received: 31 July 2020 / Accepted: 31 March 2021 / Published online: 23 April 2021 \\ (C) The Geneva Association 2021
}

\begin{abstract}
This study investigates the potential effect of economic policy uncertainty, geopolitical risk, non-oil output, inflation and corporate governance features on insurance companies in Saudi Arabia using quarterly data over the period 2013-2019. More specifically, we apply estimation method panel autoregressive distributed lag (ARDL) to model the long- and short-term relationships. Our empirical results reveal negative short-term effects of geopolitical risk and uncertainty about government economic policy on insurance demand. However, the effect of the latter is not permanent. Our results support the assumed 'demand following theory' in the longterm, which, in turn, is an indication of the fact that the demand for insurance policies is dependent on economic growth and more susceptible to inflation. Our evidence shows that corporate governance has a significant effect on insurance demand in the long term, whereas a Shariah board has no significant impact.
\end{abstract}

Keywords Geopolitical risk · World uncertainty index · Insurance $\cdot$ Corporate governance $\cdot$ Panel-ARDL model

\section{Introduction}

In light of the current financial and economic crises, the association between insurance activities and real income have increasingly come under scrutiny, because insurers might provide a broad range of financial products and services not only to policyholders but also to investors and financial markets (see, for instance, Gaganis et al. 2020; Liu et al. 2016). Going by the bulk of research conducted in this field,

Wael Hemrit

wahemrit@imamu.edu.sa

1 Department of Insurance and Risk Management, College of Economics and Administrative Sciences, Imam Mohammad Ibn Saud Islamic University (IMSIU), P.O. Box 5701, Riyadh, Saudi Arabia

2 GEF2A Laboratory, ISG Tunis, University of Tunis, Tunis, Tunisia

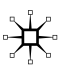


one of the main principles that explains how economic activities speed up financial development is 'demand-following theory'. According to this theory, as the real side of the economy expands, the demand for financial services increases, allowing all financial parties to provide many financial services and build new revenue streams (Robinson 1952). Thus, advocators of this theory tend to set up a free market system, which can mobilise resources for financial investment so as to promote macrofinancial stability and foster the emergence of growth-enhancing financial markets and intermediaries. For a scoping review of the extant empirical literature on this view of the insurance-growth nexus, see Lee and Lee (2020), Dash et al. (2018), Pradhan et al. (2017) and Haiss and Sümegi (2008).

Most empirical evidence focuses on the impact of insurance demand (hereafter ID) on economic growth (Lee et al. 2016; Shahbaz et al. 2013) within the framework of unleashing of endogenous growth theory. However, the effect of economic growth on ID has not yet been fully clarified, and no empirical evidence has yet been presented. Also, inflation is a real concern for life and non-life insurance because it can affect investment returns, asset valuations and future insurance liabilities. Therefore, mention must be made here of the fact that we have attempted to determine the effect of non-oil GDP and inflation on ID.

Moreover, recent crises have increased the need for research on economic uncertainty to deepen existing knowledge on concepts related to the existence, effects and consequences of and methods for avoiding the build up of uncertainty. Considering government and liberalisation policies and their relevance for financial sector development, the extant literature suggests that there are increasing concerns about newsbased policy uncertainty, tax legislation expiration and dispersion in economic forecasts, which ultimately lead to financial perturbations (Lee et al. 2020; Al-Thaqeb and Algharabali 2019; Baker et al. 2016). From a financial perspective, economic uncertainty is largely based on the idea that uncertainty is one of the biggest drivers of stock and bond market return volatility (Fang et al. 2017), the cost of capital and innovation processes (Xu 2020), credit risk and interest rates for banks (Ashraf and Shen 2019), and information asymmetry and management disclosures (Nagar et al. 2018). Collected premiums lead to an increase in an insurance company's investment returns and this makes it possible for the insurer to lower its premium prices in the future, which makes its policies more attractive to clients. Policy uncertainty in economic decisions reflects the chance that the actual return on an investment, or its gain or loss over a specific period, is lower than expected (Balcilar et al. 2020). Thus, in case of unfavourable economic policy changes, a higher difference between returns will keep the cost of insurance premiums high to protect investment profit and key shareholders satisfied. Furthermore, background uncertainty can alter insurers' risk-taking behaviour, inducing them to act in a more risk-averse manner by increasing the cost of insurance premiums. Given this, the question that naturally emerges is how economic policy uncertainty impacts the expansion of insurance activities. This current empirical vacuum is remarkable, given that expected utility theory holds that the demand for insurance services can be explained as a demand for certainty.

In this work, we focus on economic policy uncertainty for multiple reasons. First, although some studies find that uncertainty affects market correlation and portfolio 
performance, less is known about its effect on financial intermediaries, especially in the insurance sector. Second, by distributing the risk among a group of people, the life and non-life insurance industries offer a low-cost approach to providing risk transfer and indemnification and promoting household consumption. Thus, insurance behaviour depends on the simplified conditions of partial certainty, where the assumption is that the insurer can accurately forecast underwriting and investment outputs. Third, policy uncertainty may impose a wide array of constraints on financial security development for all citizens or selected cohorts, ${ }^{1}$ which may (1) complicate the control of insurance market conduct with regard to pursuing legitimate interests and the rights of the less informed and (2) amplify the lemons and agency problems (Nagar et al. 2018).

The increasing loss of control over decisions and actions, with regard to economic and financial markets, makes it crucial for regulators, financial institutions and investors to keep geopolitical risk (GPRS) in mind. According to Bloomberg (2019), GPRS includes a broad range of economic or political threats (e.g. terrorism, war, cyber incidents etc.) as well as normal incidents that take place regularly in some nations (e.g. elections, congressional or parliamentary actions, and the push and pull of political movements in general). Lee and Lee (2020) suggest that, despite the genuine efforts and discussions that have pointed out the insurance growth nexus, there exists a striking paucity of corresponding empirical research where GPRS is concerned. Understandably, events such as acts of terrorism, political instability, tensions and friction among nations affect the vibrancy of capital markets and all economic activity to a certain extent, and thus have a great influence on investor sentiment and the need for insurance coverage, which is likely to rise (OlasehindeWilliams and Balcilar 2020). Banks, investors and firms are urgently looking for the safest areas (insurers, from their point of view) to transfer the consequences of miscalculating GPRS, which can be drastic and they keep searching for coverage against potential threats. While the safest areas will also be the most restrictive in this case, insurance policies will contain special or restrictive provisions and will have higher premiums. The relevance of this risk in explaining the need for insurance services is somewhat intuitive.

As part of the ongoing debate in empirical research on the significance of GPRS and economic policy uncertainty, our study sets out to examine their effects on ID in Saudi Arabia, the biggest economy in the Middle East and one of the largest producers of crude oil in the world. Under the auspices of Vision 2030, Saudi Arabia remains firmly on the transition path from an oil-based economy to one that is more broad-based. It experienced slower economic growth during 2015-2017 after the stunning fall in oil prices, although some recovery is now underway. After a decade of a strong economic activity from 2004 to 2013, during which average real nonoil GDP growth was 7.5\%, growth slowed down during 2014-2019 to reach $2.92 \%$ and was projected to reach $2.5 \%$ in 2019 (International Monetary Fund 2019). To a large degree, the GPRS inherent in the trends and events that shaped the last decade

\footnotetext{
${ }^{1}$ For example, health insurance and pensions, workers' compensation and other compulsory liability insurance.
} 
in Saudi Arabia arises from many issues. The principal cause is the escalation in tensions between Iran and Saudi Arabia. Another important issue is the war and vicious conflict in Yemen. The huge effect of the diplomatic crisis with Qatar and the unprecedented upward and downward jumps in oil prices and aggregate demand over the last five years are also undeniable ( $\mathrm{Su}$ et al. 2019). As a result of recent heightened GPRS, the environment has proved to be more challenging for the insurance industry in Saudi Arabia ever since. Since the state monopoly on insurance was ended in 2004, all insurance companies operate in accordance with the Takaful model. ${ }^{2}$ The sector faced challenging times over the last decade and, according to the Fitch Credit Ratings report (2020), insurance penetration remained one of the lowest in the world, at $1.7 \%$ of GDP, and business is still based on the compulsory lines of health and motor cover (which collectively form more than $80 \%$ of the market). Thus, there is an imperious need for investigation into the effect of GPRS on ID for proposing policy direction for policymakers and insurers in Saudi Arabia.

Focusing on corporate governance issues in the worldwide insurance services industry, good governance has been found to lead to both high performance and congruence of the organisation's actions and values with ethical norms (Hemrit 2020; Alhassan and Boakye 2020; Lambalk and De Graaf 2017; Kader et al. 2014). Agency theory emphasises that the principal-agent relationships should lead to the efficient organisation of information and risk-bearing costs (Jensen and Meckling 1976). Therefore, as Shleifer and Vishny (1997) put it, a firm with weaker governance has greater litigation risk and agency costs arising from the divergence of interests between shareholders and corporate managers. In the Islamic finance context, Takaful insurance companies (TKIs) let shareholders and policyholders share the surplus arising from the use of contributed insurance capital on a profit-sharing basis. Agency problems will be apprehended by financial markets and reflected in a company's anti-takeover provisions and reduced firm value, as well as subsequent insurance surplus. In this case, the insurer will charge more than its insurance policy is worth to consumers and can risk alienating them. Hemrit (2020) and Kader et al. (2014) derive the optimal board size and independence of members, as the lynchpin of corporate governance, not only to improve shareholder value but also to achieve fair insurance premium distribution.

We extend this line of research by linking corporate governance structure with ID in Saudi Arabia. We investigate the following research question: Can corporate governance explain the demand for insurance policies in TKIs?

We employ a comprehensive sample of 24 insurance companies operating in Saudi Arabia from 2013 (Q1) to 2019 (Q4). For analysis, we use the recently published quarterly World Uncertainty Index (WUIN) of Baker et al. (2020), as a new quarterly measure of uncertainty. It is constructed by text-mining the country reports from the Economist Intelligence Unit (EIU) (Ahir et al. 2018). Furthermore, we use

\footnotetext{
2 The Takaful model is based on the concept of brotherhood, solidarity and mutual cooperation among participants (insured) to achieve well-being of those who need to cover damage, misfortune and losses, with no intention of making profit (Akhter 2010). The profit and underwriting surplus are distributed entirely to the participants.
} 
the GPRS index of Caldara and Iacoviello (2018), counting the frequency of specific words related to tensions and geopolitical acts in the main newspapers. Moreover, we use insurance-level data from quarterly financial reports. To this effect, the panel autoregressive distributed lag (ARDL) technique (pooled mean group, PMG) is applied as our econometric methodology.

The study has the following objectives: first, we aim to provide a better understanding of WUIN effects on ID in Saudi Arabia. Given that rising uncertainty is pervading the success of non-oil sectors and contributing to economic growth and fiscal sustainability (notably trade tensions), our findings provide implications for insurers to extend their coverage and capacity within and around non-oil industries in petroleum countries and other emerging economies. Second, we highlight the impact of GPRS on the development of the insurance market in Saudi Arabia, which rose, according to Reuters (2019), to the highest GPRS in the region. Third, our study examines the effect of non-oil GDP and inflation on ID and which is leading or lagging due to geopolitical actions. Fourth, we assess both the long- and shortterm relationship between ID and GPRS and WUIN. Fifth, we examine the impact of corporate governance variables to identify crucial factors that support the building of confidence in insurance products, attraction of positive investment flows and increases in ID. Using the panel ARDL technique, we postulate that GPRS and WUIN have a significant short-term negative impact on ID. However, the effect of WUIN was less prominent in the long term. We also find that increasing non-oil GDP growth, as a key measure of economic activity (excluding the oil sector), is positively linked to ID, confirming the results of most previous studies. Moreover, the long-term effect of inflation on ID is often quite different from its short-term effect; the long-term effects are positive (and negative in the short term). As to corporate governance, our results argue that the number of independent board members is negatively linked to ID and the effect of board size is positive and statistically significant in the long-term. However, all estimates turn out to be insignificant in the short term. Finally, the size of the Sharia supervisory board is found to have no significant effect on ID.

We contribute to the existing literature in several ways. First, our study complements existing works that examine the impact of WUIN and GPRS on firms' financing and investment and banks' loan pricing (Xu 2020; Su et al. 2020; Ashraf and Shen 2019). Thus, we extend this debate to insurance companies, as this sector is an ideal testing ground due to strong omnifarious characteristics (Lambalk and De Graaf 2017), by assessing the impact of the uncertainty resulting from WUIN and GPRS on ID. Second, we extend the literature by combining the perceived uncertainty of the state of the economy and geopolitical issues from two recent and specific uncertainty indices: the World Uncertainty Index (Ahir et al. 2018) and the Geopolitical Risk Index (Caldara and Iacoviello 2018). The advent of macro risk indicators such as the WUIN and GPRS has made it possible to carry out macrolevel studies on the nexus between insurance and uncertainty. Third, in contrast to prior studies, we place more effort on TKIs. By doing so, our study will help to provide some insight on ID by introducing the Shariah supervisory board with structural elements characteristic to corporate governance as explanatory variables that generalise those used when referring to conventional insurance (Gupta et al. 2019). 
Fourth, this study is distinguished from previous works because it employs not only the Westerlund and Edgerton (2007) cointegration and Granger causality methods, but also panel ARDL, which tends to be more efficient in assessing the long-run connection data in small samples and it performs well irrespective of whether our variables are stationary, non-stationary or even mutually cointegrated (Pesaran and Shin 1999). In this context, our findings might be relevant to regulators of countries in which Takaful products are witnessing substantial growth and are competitive with equivalent conventional insurance products.

In summary, this study provides an appraisal of the effect of economic policy uncertainty and GPRS on ID for the benefit of the insurance sector and policymakers. In addition, this article also considers the role of corporate governance and income level in the Saudi Arabian insurance market. This is mainly because the literature has found real income to be the most significant stimulant of insurance sector development.

The remainder of this paper is structured as follows. The next section reviews the literature, followed by a section defining the methodology and data. Then, the results are presented, and the final section concludes.

\section{Related literature}

\section{Economic policy uncertainty and corporate finance}

The importance of uncertainty surrounding economic policies at the financial market, portfolio allocation and risk management levels is well established (Baker et al. 2016; Bernal et al. 2016; Karnizova and Li 2014). However, there is little research on the role of uncertainty in determining insurance choices not only in an internal context (upward pressure on the cost of insurance and reinsurance and increased managerial risk aversion), but also in an external one (increased friction with insurance consumers, bubbles and regulatory frictions in trade and investment).

This paper therefore contributes to the nascent but important literature on economic policy uncertainty initiated by the influential work of Bloom (2009), who suggests that during times of uncertainty, investing and spending may have proven to be unattractive to the average household, as firms seemed strangely reluctant to develop good decision-making practices in challenging and uncertain regulatory economic environments. According to Al-Thaqeb and Algharabali (2019), uncertainty has the potential to negatively affect cash flow and the financial condition of the company.

Currently, only a limited number of studies have reported the association between uncertainty and ID. None, to our knowledge, studied the effect of economic policy uncertainty on demand for Takaful products. Using a non-linear autoregressive distributed lags model, Gupta et al. (2019) suggest that uncertainty about economy policy decreases the demand for life insurance premiums and has a positive effect on that of non-life insurance premiums. However, they used only GDP as a real output, which may produce a biased measure of inflation and an inadequate measure of welfare or even economic well-being, as can be witnessed by the recent financial crisis. 
Rising uncertainty in political and economic events increases adverse selection and moral hazard problems; thus, insurance companies reduce exposure to large claims by limiting coverage or raising premiums. As it becomes increasingly difficult for insurers to distinguish underwriting and credit risks during uncertain times, there is a decline in offering various insurance policies and services to address policyholders' needs. The growth of uncertainty extends and deepens conflicts within and between investors with regards to the predictability of financing costs and difficulties in raising capital to fund profitable projects. In addition, heightened uncertainty around company investment perspectives can lead to a rise in risk premia, which in turn directly affects insurance pricing and consumption. Focusing on a panel of 15 countries, Balcilar et al. (2020) provide sufficient evidence in support of a shortrun positive association between economic policy uncertainty and both non-life and life insurance premiums, although the long-run effect is more significant than the short-run effect. Moreover, Biener et al. (2019) relay the uncertainty and probabilities attached to economic outcomes within a large behavioural experiment. They establish empirically that ID significantly decreases when introducing uncertainty. In addition to concerns about the effect of uncertainty on ID, Balbàs et al. (2015) assume that, in the presence of uncertainty, reinsurer ambiguity is higher than that of insurers, which may put pressure on direct insurers by restricting their choice of insured risks and levels of coverage.

\section{Geopolitical risk in the financial context}

Some have recently aimed to review the current evidence on the effects of GPRS, especially the effect of risk associated with wars, terrorism and tensions among states on economic stability and financial development (Antonakakis et al. 2017; Shahbaz et al. 2013). Focus has now turned to the financial market response to GPRS, with policymakers proposing their preferred policy tools-ranging from balance in international liquidity and an increase in trade. For example, the nonparametric causality-in-quantiles test is proposed by Balcilar et al. (2018) to explore the impact of geopolitical tensions on the stock markets of G7 countries. They find strong evidence of causality for the majority of stock-market returns in Europe. Khoo and Cheung (2020) find that high GPRS increases the level of information asymmetry and, in return, that public debt financing costs increase with the debt level. Caldara and Iacoviello (2018) show that this risk leads to direct or indirect repression of returns in developed stock markets. The impact of geopolitical events has also been considered with respect to gold volatility (Balcilar et al. 2016) and Bitcoin (Al Mamun et al. 2020). As to the financial intermediaries' outlook, very little literature has found that GPRS deteriorates firms' future performance and corporate financing (Khoo and Cheung 2020). The insurance industry, as one of the most important financial sectors, plays a vital role in the economy, allowing anyone to transfer risk for a premium. The emerging literature on insolvency risk and the probability of default argue that heightened GPRS may have an increasingly visible impact on financial institutions, primarily through their investment portfolios, because crises can spread quickly. Insurance companies may then have difficulty 
underwriting and pricing certain risks and will face problems attracting capital investment from policyholders.

The insurance market in Saudi Arabia is in its infancy, and so prevailing conditions and the potential impact of geopolitical issues and regulatory changes affecting the U.S., Europe and some Arab Spring countries can have a spillover effect. The major presence of foreign insurance and reinsurance companies ${ }^{3}$ and the high volume of foreign direct investment (FDI) inflows in Saudi Arabia tend to enhance insurers' vulnerability to events that are not in the scope of a country's control. According to UNCTAD's World Investment Report (2019), FDI flows increased by more than $120 \%$ between 2017 and 2018 to reach USD 3.2 billion, but they were still significantly lower than in previous years. This is mainly due to political issues and falling oil prices. Therefore, foreign investors tend to worry about GPRS when deciding on which financial and non-financial markets to expand into (Baek and Qian 2011). On top of this, GPRS may make foreign investors more risk averse in general and lead to them withdrawing funds from many corporate investments. This risk will keep foreign investors' fingers on the pause button when it comes to allocating to this sector. As a result, this risk can quickly disrupt insurance and investment activities.

Furthermore, during periods of higher GPRS, government spending, consumption and the provision of credit to the private sector decreased due to uncertainty and fears about oil supply disruption in Saudi Arabia ( $\mathrm{Su}$ et al. 2019). This situation also has adverse implications for investment decisions and negative repercussions on insurance activities. Antonakakis et al. (2017) show that GPRS has a negative effect on oil returns for the petroleum-producing country, and thus it may restrict investment in the global economy, finally leading to lower property and liability risks.

\section{Corporate governance and Shariah boards in Takaful insurance}

TKIs, unlike conventional insurance, prevent violation of the terms of inheritance set by Shariah, avoiding the unfair and unethical nature of the insurance business (such as interest, gambling and uncertainty) and making transactions comply with Islamic jurisprudence. According to the IFSB report (2019), while the Takaful sector grew by $4.3 \%$ on average, a lot of global insurance premiums remained relatively untapped at USD 26.1 billion, accounting for just $2 \%$ of total Islamic finance assets. There are therefore opportunities for the sector to grow. Currently, there are few models applied, mainly based on Mudharaba, Wakala and Waqf. ${ }^{4}$

\footnotetext{
3 According to our data collected over the study period, foreign insurers maintain a $51.3 \%$ insurance market share in terms of net premiums.

4 Wakala refers to a contract where the operators (the shareholders) manage Takaful activities against an upfront agency cost; Mudharaba (profit sharing) where the operators receive investment income from technical reserves; and Waqf where operators will first generate the 'Waqf funds' through a Waqf donation. Within the tabarru' concept, participants who share the same Waqf Takaful policy would then contribute to the funds.
} 
The issue of the effectiveness and efficiency of any insurance contract in providing coverage in the way that it was intended is related to the level of satisfaction of policyholders with respect to their awareness on the utility of insurance companies, their policies and their rights to obtain any surplus-less reserves for future claims, some qualified contingencies and investment returns (Lee et al. 2020). As the shareholders act as agents on behalf of participants, the relationship between the insured and operators is that of a principal and an agent in the well-known agency problem, where the operators (agent) may not act on behalf of the principal (policyholders). Addressing this issue, Karbhari et al. (2018) suggest that the governance mechanism, by ensuring that managers act in the best interest of operators and policyholders to evade agency costs, is one of many factors to be considered when purchasing insurance policies. Moreover, governance structures and principles ensure that all economic activities and actions of the organisation conform to social norms and any deviation from the true rules of Islam is another cause of the agency problem. While corporate governance matters and has garnered a great deal of attention within the conventional insurance sector, there is a relative dearth of empirical research focusing on the corporate governance factors that play a major part in ID in the Takaful sector (Hemrit 2020; Karbhari et al. 2018; Akhter and Khan 2017; Kader et al. 2014).

Drawing on agency theory and legitimacy theory, questions pertaining to boards' powers, duties and responsibilities, and the presence of independent members have surfaced, leading to a large debate on the type of efficient systems needed in order to monitor managers' risky behaviour and maintain policyholders' confidence and duties. Najjar (2012) suggests that the board is ultimately held accountable for the actions and decisions of the insurer and that this is how to improve the functioning and sustainable development of insurance markets. Ali (2018) stipulates that board members can also offer valuable advice in establishing various insurance contracts. Another measure of the quality of corporate governance at the board level is the independence of the board members and the weight of outside directors (Boubakri 2011). Given the wide range of responsibilities and liabilities that can be attached to the role of an independent member, MacMinn et al. (2012) argue that if the majority of the corporate board members are outside directors, then the board will, ceteris paribus, act in the interests of all parties.

Similarly, Hemrit (2020) indicates that the presence of non-executive members escalates the share value of the firm. Also, much of the public debate related to corporate governance in Islamic financial institutions has centred on the size of the Shariah board. Agency theory suggests that agency conflicts and information asymmetry between operators and policyholders can be mitigated through an effective Sharia board (Safieddine 2009). Given that policyholders do not have any representation in deciding the compensation awarded to the operators on their behalf, a Shariah board ensures all policyholders are treated fairly and sends signals to the market that TKIs are not expropriating surplus from policyholders. Kwon (2007) suggests that maintenance of the highest standards of ethical principles in insurance companies attracts a large number of participants and can benefit from economies of scale. Therefore, a Shariah supervisory board may sustain the significance of contractual obligations, and thus the insurer becomes more 
attractive to capital investors and policyholders when it oversees Takaful activities' compliance with Islamic principles and jurisprudence (Kader et al. 2014). There is a dearth of literature dealing with the importance of Shariah boards and their effect on Islamic indices' performance (Hassan et al. 2018). Our study can improve our understanding of the underlying managerial economics of TKIs and, more generally, the role of Islamic corporate finance.

With the aim of satisfying shareholders' and policyholders' interests and increasing ID, it is compulsory that a suitable corporate governance system be recognised. Thus, our analysis complements the literature on how these corporate governance mechanisms affect the demand for insurance policies.

\section{Real output and insurance demand}

The previous literature is anchored on both 'the supply-leading and demand-following hypotheses' to determine whether a relationship between financial development and economic growth exists (Gupta et al. 2019; Lee et al. 2016; Haiss and Sümegi 2008). To the proponents of demand-following theory, Batuo et al. (2018) argue that safeguarding economic stability and other macroeconomic dimensions, such as vicissitudes of economic fortunes, balance sheets and changes in credit and securities markets, contribute to explaining any vulnerabilities within a financial system.

From a theoretical point of view, the allocation of resources and economic growth can contribute to insurance company growth through increased affordability of insurance products for policyholders (Redzuan et al. 2009). According to Mensi et al. (2017), the introduction of numerous key reform measures to boost non-oil revenues in Saudi Arabia helps to strengthen both the private and public investment sectors, which are conquered by a minority of the biggest drivers of business in the service sectors. The substantial increase in investment is generally accompanied by a parallel increase in risk and uncertainty, and this might result in increased insurance consumption. Thus, the non-oil sector can have potential effects in terms of triggering ID as a risk mitigating and saving tool (Hemrit and Benlagha 2019).

Another macroeconomic indicator that may affect insurance is inflation. Taking the uncertainties related to inflation rate into consideration, Balcilar et al. (2020) find that the demand for insurance products is negatively correlated with increases in inflation, resulting in a decline of insurance premiums. Han and Hung (2017) show that inflation and its volatility would reduce demand for life insurance. On the other hand, Kwak and Lim (2014) assert that the influence of expected inflation rate depends on market parameters. The persistent rise in public spending over the years until now has been tied to the unpredictable changes in oil revenues, which has led to volatile macroeconomic conditions in Saudi Arabia. Despite the merits of the above-mentioned works, more investigation is required to discover more about the simultaneous effects of non-oil GDP and inflation on risk retention and the transfer level. Table 8 in the Appendix includes a number of examples and case studies that are used to understand how the real output impacts insurance activities and vice versa. 


\section{Empirical analysis}

\section{Data}

This paper employs quarterly data of 24 insurance companies from 2013 (Q1) to 2019 (Q4) for Saudi Arabia. The empirical period depends on the availability of data. The main reason that we chose these 24 companies is that their relative market shares are higher than the remaining companies during the sample period. Given Saudi Arabia's Takaful insurance model, the entire industry must be Shariah compliant. This makes Saudi Arabia the largest Islamic insurance market in the world ${ }^{5}$; it plays a critical role in the global Takaful industry and gives a meaningful motivation to our research. The proxy of insurance activity is net premiums written (NPW) and the governance variables - board size (BSIZE), independent members (IM) and Shariah board size (SBSZ) — can be obtained from the quarterly financial statements. We collect non-oil GDP (NOGDP) and inflation rate (INF) from World Development Indicators. All variables (except INF) are expressed in the logarithmic form.

Our main proxy for WUIN is developed by Ahir et al. (2018). This new index is defined using the frequency of the word 'uncertainty' in the quarterly Economist Intelligence Unit country reports, with specific topic coverage (economic and political developments). Moreover, this index follows a standardised process and structure. Some of the largest spikes are recorded during the September 11 attacks, the SARS outbreak of 2003, the European sovereign debt crisis, El Niño, the U.K. referendum in 2016, the COVID-19 pandemic and the 2020 U.S. Election. Ahir et al. (2018) note that WUIN mitigates concerns about accuracy, ideological bias and consistency. The measure for GPRS comes from the newly constructed GPRS index by Caldara and Iacoviello (2018). ${ }^{6}$ Three-month averages were taken to transform the monthly indexes into quarterly values.

\section{Empirical model and methodology}

As mentioned previously, our main aim is to analyse how GPRS, WUIN, corporate governance variables and macroeconomic indicators influence ID by means of a panel ARDL model approach. In fact, Pesaran and Shin (1999) illustrate that even if the sample size is small, the long-run parameters are consistent and asymptotically normal, irrespective of the order of integration. Moreover, the ARDL approach is more reliable for small samples as compared to Johansen and Juselius's cointegration procedure (Haug 2002). There are many examples in the literature that use this methodology for small samples, e.g. Asteriou et al. (2020), Chudik and Pesaran (2015) and Bildirici and Kayıkçı (2013). Halicioglu (2007) suggests that there are

\footnotetext{
5 Global Takaful report 2017 (Milliman 2017).

${ }^{6}$ Caldara and Iacoviello (2018) construct the GPRS index with an algorithm that calculates the frequency of articles related to geopolitical tensions in leading international newspapers. These newspapers indicate the most geopolitical events, which often implies U.S. involvement.
} 
two specific advantages of using this method: the simultaneous estimation of shortand long-run effects and the ability to test hypotheses on the estimated coefficients in the long-run. This is not the case in the Engle-Granger method. However, for the variables in data that contain a unit root, this method will likely have difficulties in identifying the correct relationship, as issues of spurious correlation may arise. In line with the Pesaran and Shin (1999) methodology, the general $\operatorname{ARDL}(p, q, \ldots, q)$ model is as follows:

$$
Y_{i t}=\sum_{j=1}^{p-1} \gamma_{i j} y_{i, t-j}+\sum_{j=0}^{q-1} \delta_{i j} X_{i, t-j}+\vartheta_{i}+\varepsilon_{i t}
$$

Take the same $q$ for the independent variables and $\gamma_{i j}$ reflects the scalar. $X_{i, t-j}$ is a vector of $\mathrm{K} \times 1$ regressors for group $i . \vartheta_{i}$ is a group-specific effect. This model can be reparametrised as a vector error correction model system:

$$
\Delta y_{i t}=\theta_{i}\left[y_{i . t-1}-\beta_{i} X_{i, t-1}\right]+\sum_{j=1}^{p-1} \gamma_{i j} \Delta y_{i, t-j}+\sum_{j=0}^{q-1} \delta_{i j} \Delta X_{i, t-j}+\vartheta_{i}+\varepsilon_{i t}
$$

$\theta_{i}$ : group-specific speed of adjustment coefficient to the long-run status $\left(\theta_{i}<1\right)$.

Pesaran et al. (1999) propose an intermediate econometric estimator (PMG estimator), which requires that the long-term coefficients are similar whilst letting the short-term ones change between insurance company groups. This methodology was further used to estimate both the long- and short-run slope coefficients (including the speed of adjustment) and the regression intercept, in addition to causalities amidst the variables. To identify whether the PMG estimators are more efficient than those of the mean group (MG), the Hausman test should be performed. ${ }^{7}$

Aside from the PMG panel ARDL approach, we carry out a robustness test using a panel vector error correction (PVECM) technique to check for Granger causalities. Next, the stability of our model is also assessed using the cumulative sum of squares (CUSUMSQ) of the residuals and Chow breakpoint test for constancy over time. Finally, we proceed with the estimation of the impulse response functions (IRFs). Each IRF demonstrates the dynamic response of the cyclical component of ID to unit shocks in the variables examined.

\section{Descriptive and empirical results}

\section{Univariate analysis}

Table 1 illustrates the descriptive statistics and correlation matrix in our analysis. Panel A shows that the mean WUIN is 0.1378 and remains lower than the average global WUIN for the same period of study, which is equal to 0.23701 . Moreover, the

\footnotetext{
7 We test the hypothesis $\mathrm{H}_{0}$ : The pooling long-run coefficients are identical (Ho: $\mathrm{i}=\gamma \forall \mathrm{i}$ ) and vice versa.
} 
Table 1 Descriptive statistics and correlation matrix

\begin{tabular}{|c|c|c|c|c|c|c|c|}
\hline Variable & Mean & Maximum & Minimum & Std dev. & Skewness & Kurtosis & Jarque-Bera \\
\hline \multicolumn{8}{|c|}{ Panel A: Descriptive statistics of explanatory variables } \\
\hline \multicolumn{8}{|c|}{ Geopolitical risk and world uncertainty index } \\
\hline WUIN & 0.1378 & 0.4615 & 0.0000 & 0.1075 & 0.8646 & 3.8742 & $105.139 * * *$ \\
\hline GPRS & 109.204 & 162.074 & 65.658 & 24.457 & 0.0194 & 1.9746 & $29.4786 * * *$ \\
\hline \multicolumn{8}{|c|}{ Macroeconomic indicators } \\
\hline INF & 1.8464 & 4.3000 & -2.1000 & 1.6996 & -0.6969 & 2.4984 & $61.3895 * * *$ \\
\hline NOGDP & 26.590 & 26.680 & 26.4730 & 0.0579 & -0.5052 & 2.3060 & $42.0753 * * *$ \\
\hline \multicolumn{8}{|c|}{ Governance-specific variables } \\
\hline IM & 1.2721 & 2.3020 & 0.0000 & 0.4543 & -0.4224 & 2.9631 & $20.0222 * * *$ \\
\hline BSIZE & 2.0843 & 2.4850 & 1.3860 & 0.2317 & -0.8278 & 3.6352 & $88.0635 * * *$ \\
\hline \multirow[t]{2}{*}{ SBSZ } & 0.7623 & 2.3970 & 0.0000 & 0.6673 & 0.1363 & 1.9081 & $35.4605 * * *$ \\
\hline & WUIN & GPRS & INF & NOGDP & IM & BSIZE & SBSZ \\
\hline
\end{tabular}

Panel B: Pearson correlation analysis

$\begin{array}{lccccccc}\text { WUIN } & 1 & & & & & & \\ \text { GPRS } & 0.5703 * * & 1 & & & & & \\ \text { INF } & -0.6103 * * & 0.3892 * * & 1 & & & & \\ \text { NOGDP } & 0.2703 * & -0.4399 * & -0.5874 * * & 1 & & & \\ \text { IM } & 0.0021 & -0.0134 & -0.0064 & -0.0171 & 1 & & \\ \text { BSIZE } & 0.0068 & -0.0218 & 0.0261 & -0.0184 & 0.6139 * * * & 1 & \\ \text { SBSZ } & -0.0124 & 0.0089 & 0.0131 & -0.0150 & -0.1427 & 0.04606 & 1\end{array}$

Note WUIN, GPRS, INF, NOGDP, IM, BSIZE and SBSZ denote world uncertainty index, geopolitical risk, inflation rate, non-oil GDP, independent members, board size and Shariah board size (latter four in Napierian logarithm form), respectively

$* * *, * *$ and $*$ represent significance levels of $0.01,0.05$ and 0.1 , respectively

mean GPRS is equal to 109.106 and follows a platykurtic distribution because the kurtosis is less than 3. For all explicative variables, we reject the hypothesis that the disturbance term is normally distributed, as specified by the Jarque-Bera test. The reported statistics of the other variables show that all (except SBSZ) are skewed to the left.

We find that WUIN ranges from a low value of zero before the last quarter of 2013, to a high one of 0.4615 at the end of 2017. As shown in Fig. 1a, the periods of relatively high WUIN include (1) the new plan of 'Saudi Vision 2030' and subsequent developments, (2) Saudi Arabia's anti-corruption purge ordered by Saudi Crown Prince Mohammed Ibn Salman in November 2017 and (3) the decrease in crude oil prices and quantities, coupled with falling refining and chemical margins in the first half of 2019.

As illustrated in Fig. 1b, we see tremendous amounts of GPRS in Saudi Arabia, which moved very aggressively into foreign financial and oil markets over 


\section{$\mathbf{a}$}

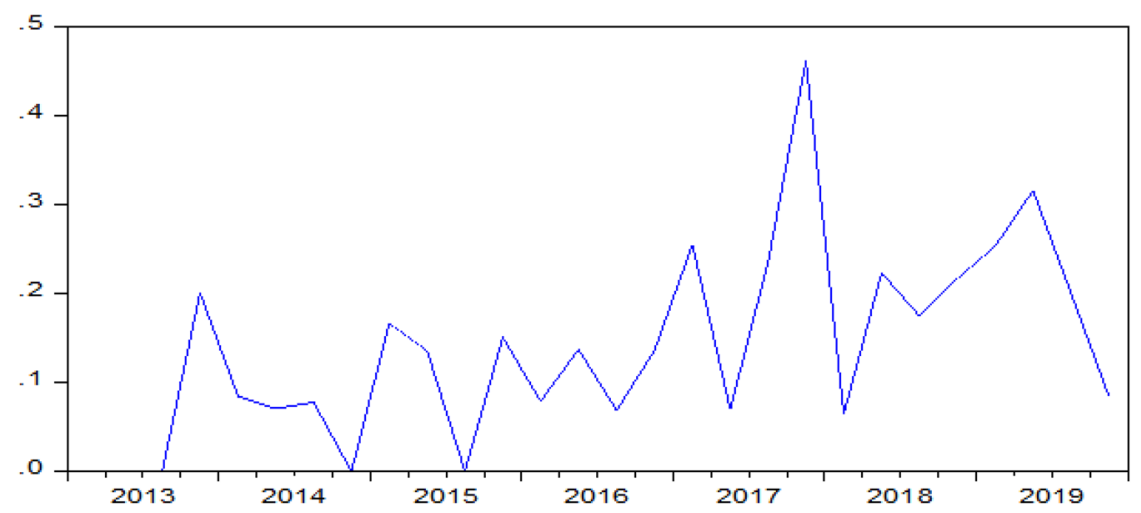

b

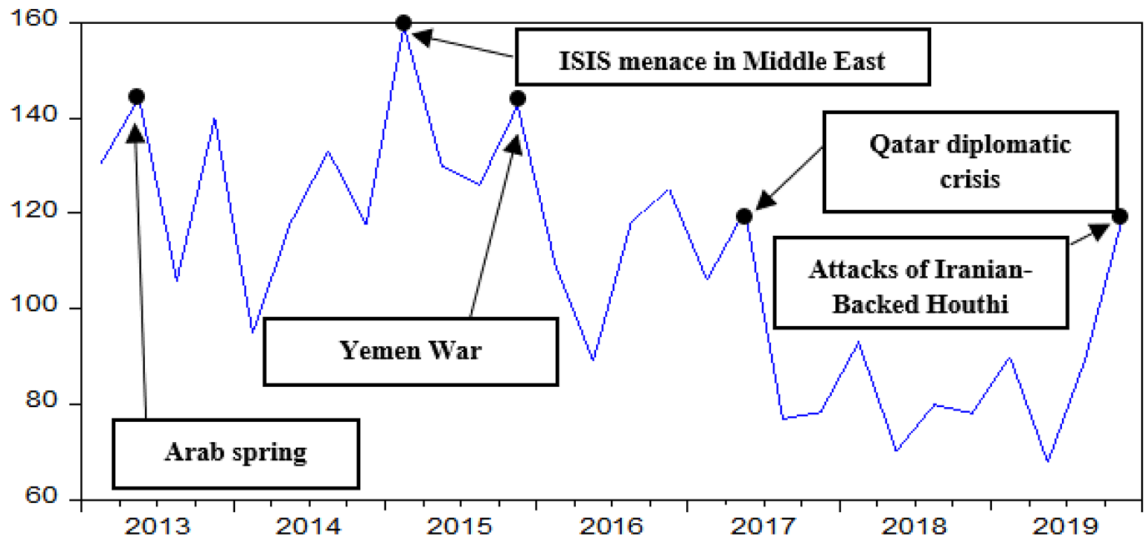

Fig. 1 a The World Uncertainty Index for Saudi Arabia. from 2013Q1 to 2019Q4. b GPRS trends in Saudi Arabia during the period of study

short-term periods, through its impact on global economy stability. ${ }^{8}$ The serious oil price collapse was a result of the Yemen War, and the ISIS threat in 2014-2015 forced Saudi Arabia to make significant changes to its economic policy (reducing public spending, imposing new taxes, 5\% -VAT, building a more diversified industrial economy, etc.) Regardless of the unprecedented financial reform efforts, and in order to boost investors' confidence and transmit credibility in insurance operations, there is an urgent necessity to ensure the development of consistent insurance regulatory practice.

\footnotetext{
${ }^{8}$ In the wake of increased GPRS, oil demand declined but stock returns increased (via addition of risk premium). As a result, the global financial system seemed on the verge of economic collapse.
} 
The correlation between WUIN, GPRS and exog. variables are reported in Panel B. The results indicate that, as expected, WUIN and GPRS are positively correlated, which is preliminary evidence that geopolitical tensions cause the greatest levels of economic uncertainty. We also find negative correlations between INF and WUIN. Also, we show that NOGDP is negatively correlated with GPRS and INF. The correlation between IM and BSIZE is statistically significant, which is consistent with prior literature (Raheja 2005).

\section{Homogeneity and cross-sectional independence tests}

When studying the panel data background, exploration of the existence or non-existence of individual effects of the data generating process is to be expected. Roughly speaking, the Hsiao test consists of testing the equality between sets of coefficients for all cross-section units. As a result, we reject the null hypothesis of slope homogeneity at the $1 \%$ level of significance (see Table $7 \mathrm{~b}$ in the Appendix). In addition to the homogeneity test, we seek to identify whether panel datasets exhibit substantial cross-sectional dependence that may arise due to the presence of common shocks (e.g. great recession, number of accidents and ill-health and environmental policies) and unobserved components that potentially have spillover effects on cross sections.

Table 2 reports the findings from the cross-dependence tests and their corresponding probability values. Pesaran (2004) suggests that the ignorance of crosssectional dependency leads to substantial bias and size distortions. In this context, we tried to run the Breusch and Pagan (1980) LM test, Pesaran (2004) scaled LM and CD tests, and Baltagi et al. (2012) bias corrected scaled LM test.

Referring to the results in Table 2, we find that the probability values for the various cross-sectional dependency tests of independent variables within each panel are significant at the $1 \%$ level (except for IM and BSIZE in Pesaran's CD test). As we can see, the $\mathrm{CD}$ test strongly rejects the null hypothesis of cross-sectional independence. In short, this shows that the analysed variables have cross-sectional dependence.

\section{Panel unit root and cointegration tests}

The first generation of panel unit root tests are founded on cross-sectional independency (e.g. Im et al. 2003; Levin et al. 2002) and may sometimes be unrealistic and restrictive (Phillips and Sul 2003). Recognising this deficiency, we should employ econometric techniques that account for these problems accordingly before conducting cointegration tests because of the problems of fallacious regressions, which may arise if the variables are not stationary. To resolve this problem, Pesaran (2007) proposes a second-generation panel unit root test, which is based on the simple averages of the individual cross-sectionally augmented Dickey-Fuller ADF statistics (CADF) and the CIPS test of Im et al. (2003). These individual statistics have similar asymptotic null distributions, not dependent on the factor loadings. The results from the panel unit root tests are reported in Table 3. 


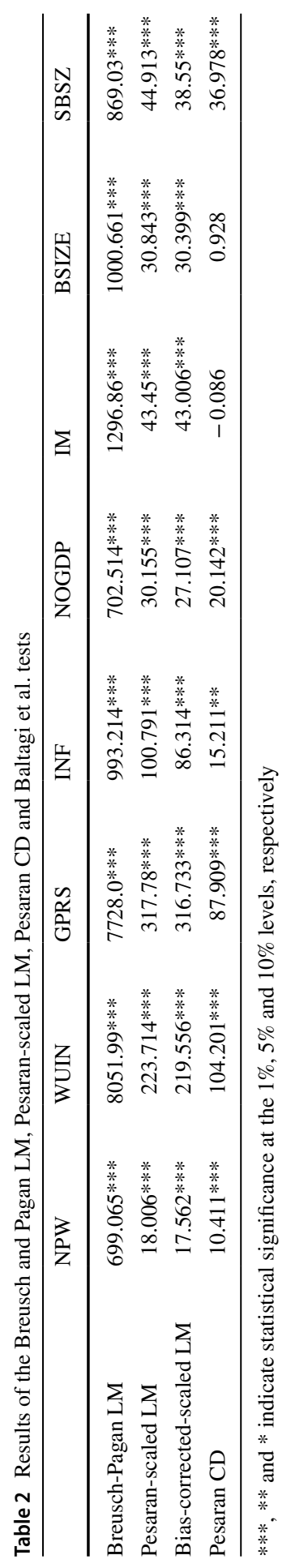


Table 3 Results from the CADF and CIPS panel unit root tests

\begin{tabular}{llll}
\hline Variable & & CADF & CIPS \\
\hline NPW & Level & $-3.33 * * *$ & $-3.20 * * *$ \\
\multirow{2}{*}{ WUIN } & 1st diff. & $-3.71 * * *$ & $-3.94 * * *$ \\
& Level & $-2.61 * * *$ & $-2.87 * * *$ \\
GPRS & 1st diff. & $-2.77 * * *$ & $-3.39 * * *$ \\
& Level & $-3.39 * * *$ & $-2.97 * * *$ \\
INF & 1st diff. & -1.84 & $-4.00 * * *$ \\
& Level & $-4.45 * * *$ & $-4.89 * * *$ \\
NOGDP & 1st diff. & $-5.14 * * *$ & $-5.67 * * *$ \\
& Level & $-3.94 * * *$ & $-4.06 * * *$ \\
IM & 1st diff. & $-4.00^{* * *}$ & $-4.23 * * *$ \\
& Level & -1.8 & -2.01 \\
BSIZE & 1st diff. & $-2.22 * * *$ & $-2.29 * * *$ \\
& Level & $-2.14 * *$ & $-2.71 * * *$ \\
SBSZ & 1st diff. & $-2.35 * * *$ & $-3.13 * * *$ \\
& Level & $-3.01 * * *$ & $-3.64 * * *$ \\
& 1st diff. & $-3.88 * * *$ & $-4.05 * * *$ \\
\hline
\end{tabular}

Notes The critical value (CV) at $10 \%$ is -2.07 ; CV5 is -2.15 ; and CV1 is -2.30

$* * *, * *$ and $*$ indicate statistical significance at the $1 \%, 5 \%$ and $10 \%$ levels, respectively

Table 4 Panel cointegration tests

\begin{tabular}{|c|c|c|c|c|c|}
\hline Within-dimension test statistics & t-stat. & Prob. & $\begin{array}{l}\text { Between-dimension } \\
\text { test statistics }\end{array}$ & t-stat. & Prob. \\
\hline \multicolumn{6}{|l|}{ Pedroni cointegration test results } \\
\hline $\begin{array}{l}\text { Panel } \\
\text { v-statistic }\end{array}$ & 0.6548 & 0.2563 & $\begin{array}{l}\text { Group } \\
\text { q-statistic }\end{array}$ & -1.3987 & 0.0809 \\
\hline $\begin{array}{l}\text { Panel } \\
\text { q-statistic }\end{array}$ & -2.1643 & 0.0152 & $\begin{array}{l}\text { Group } \\
\text { PP-statistic }\end{array}$ & -20.193 & 0.0000 \\
\hline $\begin{array}{l}\text { Panel } \\
\text { PP-statistic }\end{array}$ & -16.608 & 0.0000 & $\begin{array}{l}\text { Group } \\
\text { ADF-statistic }\end{array}$ & -6.6990 & 0.0000 \\
\hline $\begin{array}{l}\text { Panel } \\
\text { ADF-statistic }\end{array}$ & -6.2899 & 0.0000 & & & \\
\hline Kao cointegration test results & t-stat. & & Prob. & & \\
\hline $\mathrm{ADF}$ & 2.4042 & & 0.0081 & & \\
\hline
\end{tabular}

The results from both the CADF and CIPS tests show that the null hypothesis (non-stationarity) is rejected (except for IM). At certain levels there are some variables of interest that have unit roots even as in their first difference; only one variable 
Table 5 Results from the bootstrap panel cointegration test (Westerlund and Edgerton 2007)

\begin{tabular}{llr}
\hline & Value & z-value \\
\hline$G_{t}$ & $-3.372 * * *$ & -5.650 \\
$G_{\alpha}$ & -6.356 & 3.425 \\
$P_{t}$ & $-19.220 * * *$ & -8.185 \\
$P_{\alpha}$ & $-15.350 * * *$ & -4.508 \\
\hline
\end{tabular}

Note Average AIC selected lag length $=1.75$; average selected lead length $=0$. The Westerlund and Edgerton (2007) tests take no cointegration as the null hypothesis, and the test regression is fitted with a constant and one lag and lead, with the kernel bandwidth being set. Moreover, the $p$-values are for a one-sided test based on 300 bootstrap replications

***indicates statistical significance at $1 \%$

has no unit root. ${ }^{9}$ Taking first differences, we find that all variables are integrated of order one I(1), except for GPRS. We continue to test for cointegration between the analysed variables to assess the long-term link between NPW and the explicative variables using the Pedroni (2004) and Kao (1999) tests. ${ }^{10}$

Referring to the results in Tables 4 and 5, the analysed variables are cointegrated, and we have a long-run relationship. In order to avoid the consequences of failing to consider the problem of cross-section dependence and the loss of power in the procedure of first generation panel unit root tests, we employ the second generation unit root of the panel data, namely the LM bootstrap panel cointegration test, with bootstrapped $p$-values based on 300 replications (Westerlund and Edgerton 2007).

The finding with ID (as measured by NPW) indicates that the analysed variables, per their robust probability values, are cointegrated. Moreover, they retain a longterm effect, given that our null hypothesis of no cointegration is rejected for $G_{t}, P_{t}$ and $P_{\alpha}$ at the $1 \%$ level (i.e. when $\rho_{i}$ is restricted to be homogeneous). However, $\mathrm{H}_{0}$ is not rejected under the statistic $G_{\alpha}$ for all variables. To conclude, the findings of the Westerlund and Edgerton (2007) tests confirm those obtained in the Pedroni and Kao cointegration tests and prove that the cointegration evaluations for our panelwide data are valid and reliable.

\section{Long- and short-run estimation of determinants of ID with panel ARDL}

The panel ARDL estimation outcomes, for estimating the long- and short-run coefficients, are presented in Table 6. This technique consists of the estimation of the panel error correction model. For the long-run relationship, homogeneity across individuals is required, while its opposite (heterogeneity) is permitted for shortrun dynamic associations. After using the MG and PMG estimators to evaluate the

\footnotetext{
9 Traditional panel unit root tests, including Levin et al. (2002), Im et al. (2003) and Fisher type tests using ADF and PP tests, confirm our results as shown in Table C in the Appendix.

${ }^{10}$ The Pedroni (2004) test is based on computation of the residuals of the hypothesised cointegrating regression, and the Kao (1999) test is calculated by pooling all the residuals of all cross-sections in the panel.
} 
Table 6 PMG and MG estimation results

\begin{tabular}{|c|c|c|c|c|}
\hline \multirow[t]{2}{*}{ Regressor } & \multicolumn{2}{|l|}{ PMG } & \multicolumn{2}{|l|}{ MG } \\
\hline & LR & SR & LR & SR \\
\hline WUIN & $-2.17 * *$ & & $-2.25^{* *}$ & \\
\hline GPRS & 1.42 & & $-2.54 * *$ & \\
\hline INF & $2.16^{* *}$ & & $2.56^{* *}$ & \\
\hline NOGDP & $7.20 * * *$ & & $3.09 * * *$ & \\
\hline IM & $-2.96^{* * *}$ & & $-1.67 *$ & \\
\hline BSIZE & $5.00 * * *$ & & -0.04 & \\
\hline SBSZ & -0.79 & & -0.19 & \\
\hline ECT & $-7.86^{* * *}$ & & $-10.86^{* * *}$ & \\
\hline$\Delta$ WUIN & & $-4.80 * * *$ & & $-3.31 * * *$ \\
\hline$\Delta$ GPRS & & $-2.73 * * *$ & & $-3.27 * * *$ \\
\hline$\Delta \mathrm{INF}$ & & $-2.57 * * *$ & & $-2.2 * *$ \\
\hline$\Delta$ NOGDP & & -0.38 & & $-4.07 * * *$ \\
\hline$\Delta \mathrm{IM}$ & & -0.02 & & 0.39 \\
\hline$\Delta \mathrm{BSIZE}$ & & -1.37 & & -0.59 \\
\hline$\Delta$ SBSZ & & 1.46 & & 1.35 \\
\hline $\mathrm{C}$ & & $-6.65^{* * *}$ & & $-3.42 * * *$ \\
\hline Hausman-test $\mathrm{Chi}^{2}(7)$ & 2.70 & & & \\
\hline$p$ value & 0.9116 & & & \\
\hline
\end{tabular}

Note Estimations are done by using the (xtpmg) routine in Stata. Pooled mean group and mean group, all controlling for the company and time effects. While the first panel (LR) shows long-run effects, the second panel reports both short-run effects (SR) and the speed of adjustment (ec). The lag structure is ARDL $(0,0,0,0,1,0,0)$ and the order of variables is WUIN, GPRS, INF, $\ln$ NOGDP, $\ln$ IM, $\ln \mathrm{BSIZE}$ and $\ln$ SBSZ. All insurance companies, quarterly data 2013-2019. Source: Author's estimations

$*, * *$, and $* * *$ indicate significance at $10 \%, 5 \%$ and $1 \%$, respectively

long-term effect of independent variables on ID in our panel, we apply the Hausman test to measure the efficiency and consistency of the estimates of MG, PMG, and to choose the appropriate estimation method in order to control the long-run settings.

According to our findings, it seems that the long-run heterogeneity hypothesis is accepted, and evidently the PMG estimation technique is more appropriate. Also, the error-correction coefficient turns out to be meaningful and negative. This result highlights the long-term relationships in the group based on this negative sign.

The main noteworthy feature of our findings is that the influence of WUIN on ID is negative and statistically significant (at least at the 5\% level) in both the long term $(-2.17)$ and short term (-4.8), which is in line with our baseline hypothesis. The correlation between WUIN and ID confirms the finding of Biener et al. (2019). Thus, any factors that disrupt information possessed by insurers leads to an upsurge in informational asymmetry difficulties and, consequently, they fail to postpone their expansion to a more certain period (Demir and Ersan 2017).

The uncertainty around future economic and financial transitions lends a pessimistic outlook, leading to the provision of inadequate coverage or even market 
failure. In other words, the main contention with Saudi Arabia's Vision 2030 and its associated executive programmes is the uncertainty surrounding the effective and coherent implementation of the wide-ranging policy reforms with the emergence of developed insurance models. These results are in line with models including ambiguity and pessimistic attitudes (Biener et al. 2019). Another explanation suggests that rising WUIN leads to a severe lack of ability (1) to identify and assess several risks, which paves the way for rising premiums and a growing concentration of high risk and (2) restriction of coverage when people want to obtain insurance policies (Rothschild and Stiglitz 1976).

In a further investigation, we test whether GPRS affects ID. We find a negative and significant coefficient in the short term at the $1 \%$ level, but a statistically insignificant one for the long term. When GPRS increases by $1 \%$, ID decreases by $2.73 \%$. This is in accordance with many previous studies, which confirmed that geopolitical instability can have a mostly negative effect on financial markets, asset allocation and diversification (Lee and Lee 2020), but contradicts those of Shahbaz et al. (2018) and Ward and Zurbruegg (2002). While GPRS is becoming more complex, insurers face multiple concurrent events that impact their business. With the stunning fall in oil prices, Houthi attacks and the geopolitical implications of stronger diplomatic ties with Qatar, the government quickly accelerated fiscal reforms and is likely to reduce public investment in infrastructure and non-oil sectors, income and consumption. As a result, shareholders and managers start to lower the volume of realised investments, resulting in a reduction in the respective risks (property and liability, injury, economic loss, etc.) Given these considerations, insurance does not become a necessary tool in managing corporate risk, which may affect future affordability of coverage and dampen growth.

The long-term findings from this study show that the variable NOGDP is significant with a positive effect on ID, suggesting that higher contribution of non-oil sectors is advantageous to ID in Saudi Arabia. These results confirm those of Hemrit and Benlagha (2019), Dash et al. (2018) and Pradhan et al. (2017). One possible explanation for this effect could be the cocreation mechanism and flow of financial resources, working then to the participation of insurance companies in long-term investment financing. In contrast, this positive effect of non-oil GDP growth on ID becomes insignificant in the short-term. Moreover, while INF has a short-term negative impact on ID, long-term insurance growth would be increased.

As proposed, in the short term, higher inflation can indirectly dishearten investors, households and organisations to rapidly draw up a scale of preference of what to continue spending and saving on as prices rise. Instead of paying insurance premiums, investible funds will be directed into assets and securities that provide an inflation hedge and higher returns. Furthermore, high inflation by itself may increase claim costs on current policies and loss reserves, which in particular slow down ID over time. This result is consistent with the findings of previous studies based on power utility (Bohnert et al. 2016; Ahlgrim and D'Arcy 2012). In the long term, ID is impacted positively by inflation. The bulk of existing empirical studies supports this outcome and argues that high inflation indirectly raises awareness of guarding against uncertainty and prompts the need to make provisions against the hike in 
potential loss amounts, which can push up the need for insurance, thereby widening ID.

For the corporate governance variables, the results indicated that the effects were mostly long term. First, the high number of independent members negatively affects ID and contradicts agency theory, which proposes that independent members enhance the ability of insiders to exercise control and thereby to protect policyholders' and investors' interests. This result is consistent with the findings of Hemrit (2020) and Eling and Marek (2013). An independent majority on the board is stricter in their monitoring and direct regulation and thus deprives insurers of new opportunities for investment and the creation of specific insurance policies, which might ultimately lead to a decline in ID. Second, our findings show a long-term positive effect of board size on ID and confirm the results of Singh et al. (2018). This implies that larger sized companies can facilitate board functions and provide more quality decision-making processes and additional expertise to extend business networks with policyholders, investors and reinsurers, leading to excessive engagement in coverage activities (Kader et al. 2014). Finally, there is no significant effect of the size of the Shariah board, in accordance with the idea that conformity with Shariah principles in TKIs does not affect ID.

\section{Granger causality tests}

Table 7 shows the results of the causality estimates for both the short and long run. We find that the lagged ECM is significant with a negative sign (except for the governance variables), confirming the long-run relationship. The significance of the Wald test on the sum of lags of the independent variables in Eq. (4) is used to determine the existence of any causality relation.

Findings from the short-run estimates revealed a bidirectional causal relationship between GPRS or WUIN and NPW, signifying that both variables mutually affect each other in such a way that any movements in GPRS or WUIN lead to fluctuations in NPW and vice versa. Moreover, our results indicate the existence of a bidirectional causality running from WUIN or INF, which is consistent with the findings of Balcilar et al. (2014). Also, our findings report a significant bidirectional causality between GPRS or WUIN. This indicates that both geopolitical events and policy uncertainty should be issues of concern for Saudi Arabia.

In addition, a change in INF or NOGDP causes a change in NPW, suggesting that a rapid positive change will affect ID. The ID-NOGDP growth connection supports the demand-following view (Dash et al. 2018; Balcilar et al. 2018). A unidirectional Granger causality runs from INF or NOGDP to GPRS, indicating that the stresses associated with the changes in leading economic indicators today create a broader set of geopolitical menaces. It is noteworthy that NOGDP in Saudi Arabia is strong enough to not only cause WUIN, but also to predict INF.

We also detect a significant feedback causality between GPRS-WUIN-INF-NOGDP and NPW in the long term. We are thus able to infer that the development of Saudi Arabia's insurance sector is prone to the effect of both GPRS and WUIN. As indicated by Lee and Lee (2020), movement in GPRS 


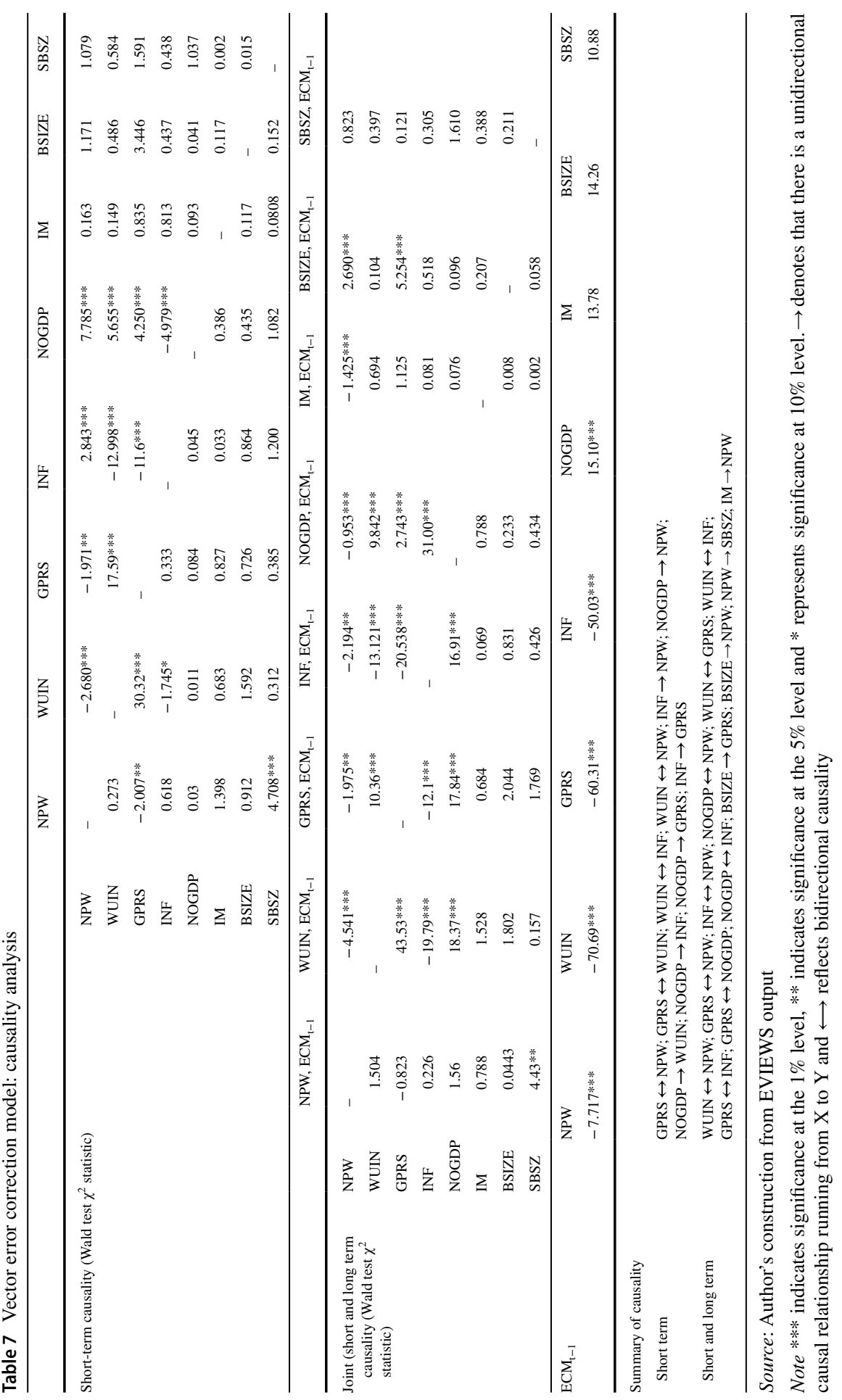


has predictive power on insurance services. Additional estimation results, like the short-term Granger causalities, support a bidirectional causality between NOGDP or INF and NPW. This supports the 'demand-following/supply-leading' insurancegrowth hypothesis. Thus, in order to improve the capacity required to achieve the ambitious goals of the insurance industry with regards to 'Vision 2030', Saudi Arabia needs to be more concerned about key measures of economic performance. The GPRS-NOGDP or INF causality in the long term suggests that changes in GPRS have a significant impact on economic conditions and vice versa, which confirms the recent findings of Su et al. (2020) for Venezuela. This result indicates that INF is adversely affected by WUIN or NOGDP with a significant two-way Granger causality running from WUIN to GPRS. Thus, uncertainty in economic policy in Saudi Arabia and GPRS reinforce each other. Lastly, there is a unidirectional Granger causality for characteristics of the board, such as IM or BSIZE, to NPW, supporting the findings of several studies (Hemrit 2020; Karbhari et al. 2018; Najjar 2012).

\section{Stability of the estimated parameters}

We test for the stability of the long- and short-term estimated parameters from our ARDL model by using CUSUM and CUSUM square (CUSUMSQ) tests (Pesaran and Shin 1999). Our result suggests that CUSUM statistics are plotted outside the critical bounds and implies that ID is not stable. However, according to the CUSUMSQ graph (presented in Fig. 2), we find that the plot of recursive residuals lies within the critical tail at a 5\% level of significance. Thus, there is no evidence of instability in the estimated parameters for ARDL estimation.

The Chow breakpoint tests suggest that the ARDL estimates of the parameters are stable over time and do not illustrate any variability (the estimated F-statistic is 1.17 with a $p$-value of 0.37 ). Thus, we accept the null hypothesis of no structural break and hence no effect on the ARDL bound testing equation. This indicates that the ARDL model seems to be steady and suitable.

\section{Impulse response functions}

The IRFs capture the dynamic responses of the cyclical component of our variable of interest to unit shocks in the examined variables (Fig. 3). The IRF graphs are a snapshot of one time period improvement on the prospective variation in values, and the changes in GPRS, WUIN, macroeconomic indicators and governance variables.

Generally, there are no persistent effects and thus our model seems to be stable. All effects for the ARDL model presented in Fig. 3 appear to be short-term and indicate that NPW behaves as an exogenous variable and that the maximum strength of shocks are explained by its own innovation.

Economic policy uncertainty has exerted a certain effect on NPW in the short run, yet with different magnitude and time profile. The effect of WUIN tends to die out, usually in less than around six months. The negative response of NPW occurs immediately after GPRS shocks and lasts for around seven months. Additionally, the IFRs between INF and NPW show that the rise in inflation leads to a reduction in ID 


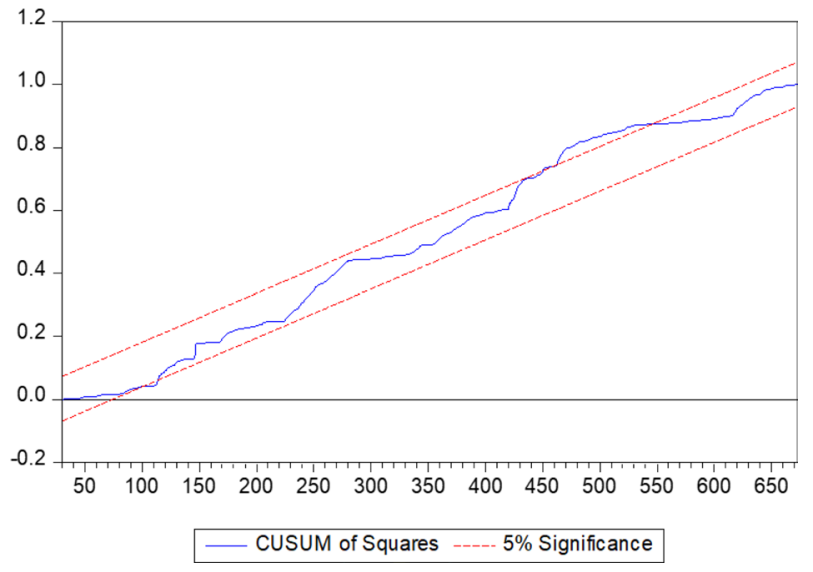

Fig. 2 Graph of cumulative sum of squares of recursive residuals

because of the decline in the currency's value, and thus purchasing power of households. In addition, insurance premiums rose more sharply, also leading to a decrease in anticipated demand for insurance coverage (Akhter and Khan 2017). Finally, it is also established that BSIZE and SBSZ may have the opposite effect on NPW, but this effect is not very significant.

\section{Conclusion}

Using the panel ARDL model, this paper addresses the key question of whether GPRS, WUIN, macroeconomic factors and corporate governance affect ID. Our main finding provides novel evidence on geopolitical risk and economic policy uncertainty as fundamental factors that can lead to inadequate insurance coverage in the short term. This implies that uncertainty and geopolitical issues can offer insight into the way in which incomplete information possessed by insurance companies on certain attributes of policyholders can lead to market failure and increase the cost of insurance, ultimately reducing the demand for insurance. We found a roughly similar long-term effect for geopolitical risk, but the uncertainty index becomes statistically insignificant. It seems that in the short run, increases in inflation can have a negative effect on ID and may lead to policyholders abandoning their insurance policies, as well as increasing wage costs for insurers. However, we establish empirically that higher inflation significantly increases the demand for insurance in the long term.

The results confirm conclusions on 'demand following theory' from earlier studies concerning the positive and short-term influence of non-oil GDP on ID. In other words, improved economic activity and the implementation and development of non-oil sectors lead to rapid expansion that also entails high risks and potential losses in the long term. As a result, economic growth can stimulate growth of aggregate ID. Finally, in the long term, the results even suggest that the proportion of independent members on the board has a negative effect on ID, while the board size 


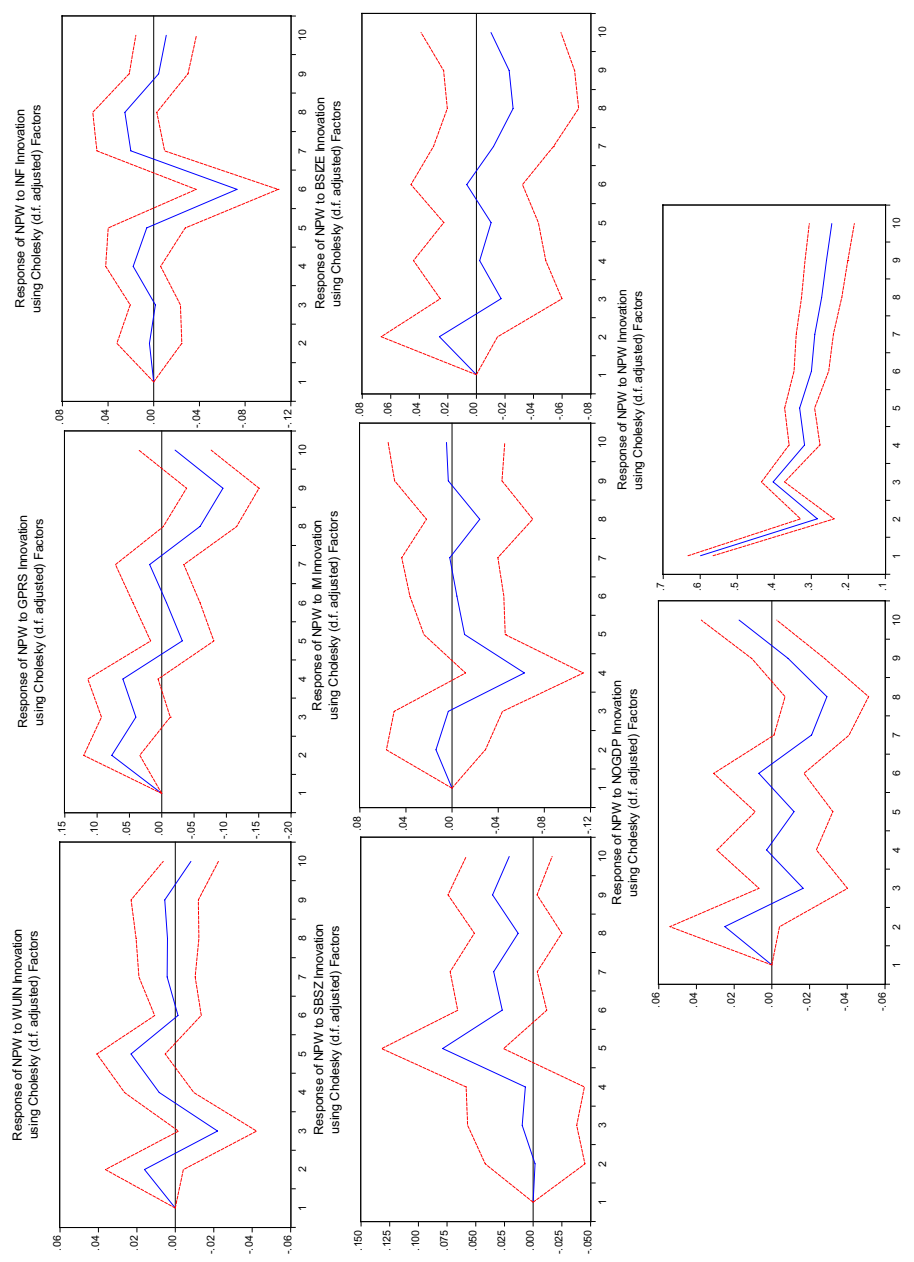

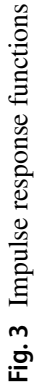

s. 
has a positive effect-however, there were no significant predictors for ID in the short term. It is also interesting to consider the possible effect of a Shariah board on Takaful ID. We find no significant effects for Shariah board size on the demand for insurance policies.

Our study also emphasies the importance of analysing the causality between ID and other variables. The evidence shows bidirectional causality among NPW, GPRS and economic policy uncertainty, and this supports the assertion that ID and uncertainty related to geopolitical tensions are interdependently related. Moreover, the result of the Granger causality test indicates a unidirectional (bidirectional) effect of changes in economic conditions in the market on ID in the short term (long term). Our findings thus fill these unsolved gaps from previous studies and provide some insight into recent conflicting results.

Our results have significant implications for policymakers, insurers and policyholders. Considering the political and institutional challenges associated with Saudi Vision 2030 and its likelihood of success, policymakers should be more concerned about the incidence of geopolitical strife in the region and the incertitude involved when building support and reforms for new insurance coverage strategies and product pricing. This can be done by reducing the cost of doing business through lower insurance costs to gain investors' and policyholders' confidence in these uncertain times. As the world's biggest oil producer, much attention should be given to increasing the share of non-oil sector revenue in Saudi Arabia. Regardless of how the oil price is ultimately determined, the government holds the key to rapid growth in the insurance industry. Insurers must consider the informational asymmetry stemming from economic uncertainty and categorise various classes of policies and implement an appropriate risk pooling strategy in accordance with the adage that 'what gets measured gets managed'. Consistent with the argument that increases in uncertainty lead to increases in insurance premiums, greater awareness of the fact that economic policy-related risks, geopolitical risks and economic policy uncertainty exacerbate financial frictions and affect firms' abilities to cover pure risks is needed. The profound impact of uncertainty on insurance activities puts pressure on individuals to bear the risk themselves, without transferring it to insurers. Given that health and protection \& savings business lines vary by size and principles in Takaful insurance in Saudi Arabia (SAMA 2018), our theoretical hypothesis could also be analysed by looking at the difference between various insurance activities. It will also be interesting to undertake research for other proxies of ID. To further explore this issue, one could conceivably extend our study to include the effects of corruption-induced uncertainty, fiscal policy uncertainty or pandemic uncertainty on ID in order to examine a wider range of uncertainties that have an impact on economic activity.

\section{Appendix}

See Tables 8, 9 and 10 . 


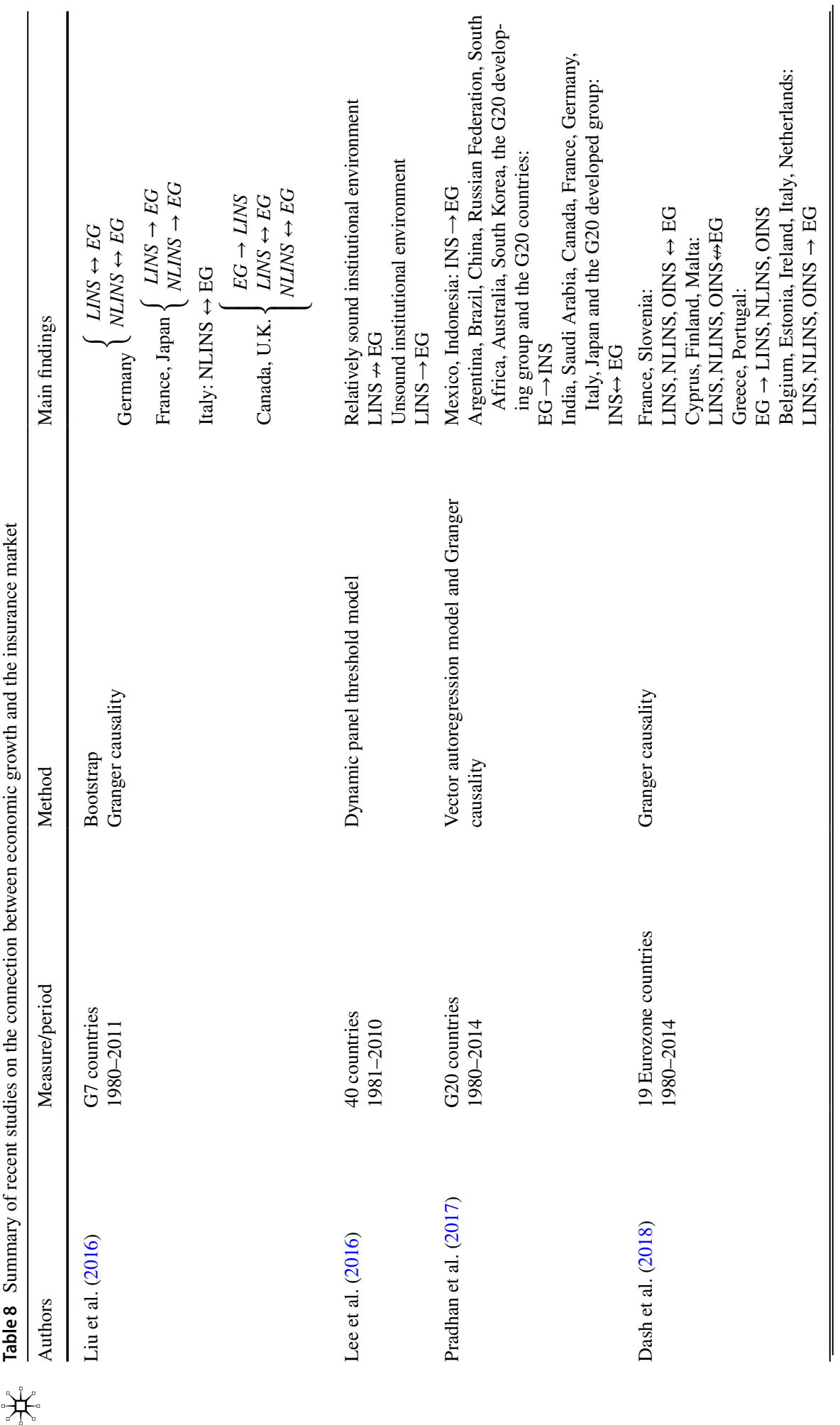




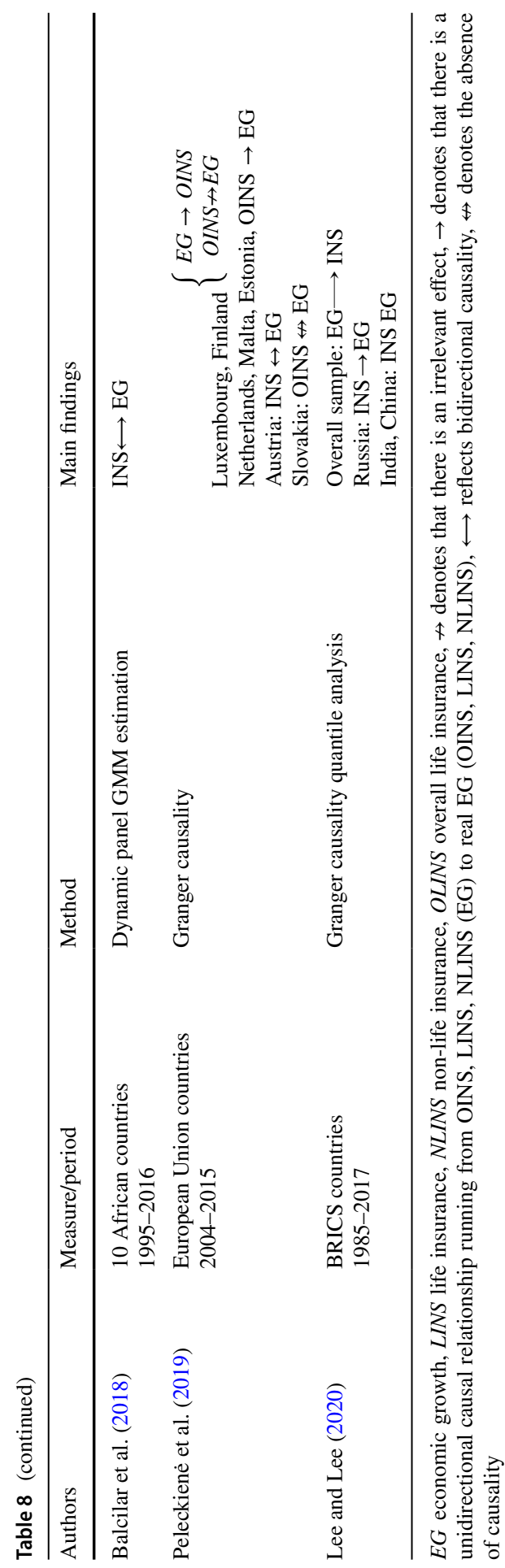


Table 9 Hsiao's homogeneity tests

\begin{tabular}{lcc}
\hline & F-stat. & Prob. \\
\hline$H_{0}^{1:}$ & 2.3533 & 0.0000 \\
Panel is homogenous $v s$ alternative $H_{\text {alt }}^{1}$ & & \\
$H_{\text {alt }}^{1}:$ & -25.931 & 0.3714 \\
$H_{2} v s$ alternative hypothesis: panel is heterogeneous & & 0.0 .0000 \\
$H_{2}:$ & 718.545 & \\
Panel is homogenous $v s H_{a l t}^{1}$ & & \\
\hline
\end{tabular}

Table 10 Results of the unit root tests

\begin{tabular}{|c|c|c|c|c|c|c|c|c|}
\hline & \multirow{2}{*}{$\begin{array}{l}\text { Levin et al. } \\
\text { Level }\end{array}$} & & \multicolumn{2}{|c|}{ Im et al. W-stat } & \multicolumn{2}{|c|}{ ADF - F. Chi-sq. } & \multicolumn{2}{|c|}{ PP - F. Chi-sq. } \\
\hline & & & Level & $\Delta$ & Level & $\Delta$ & Level & $\Delta$ \\
\hline NPW & $4.514 * * *$ & $-15.019 * * *$ & $-6.610^{* * *}$ & $-20.115^{* * *}$ & $133.498 * * *$ & $402.095^{* * *}$ & $248.409^{* * *}$ & $606.118^{* * *}$ \\
\hline WUIN & $-8.79 * * *$ & $-27.695^{* * *}$ & $-7.640 * * *$ & $-29.421 * * *$ & $141.436 * * *$ & $598.816^{* * * *}$ & $275.610 * * *$ & $482.238^{* * * *}$ \\
\hline GPRS & $-4.10^{* * *}$ & $-15.806^{* * *}$ & $-2.481 * * *$ & $-21.365^{* * *}$ & 59.129 & $442.096^{* * *}$ & $124.448 * * *$ & $807.763^{* * *}$ \\
\hline INF & -0.902 & $-12.95^{* * *}$ & $-3.721 * * *$ & $-10.065^{* * *}$ & $76.023 * * *$ & $188.221 * * *$ & $64.057^{*}$ & $334.736^{* * *}$ \\
\hline NOGDP & $-8.159 * * *$ & $-55.911 * * *$ & $-4.195 * * *$ & $-54.319^{* * *}$ & $83.022 * * *$ & $796.915^{* * *}$ & 44.556 & $518.487 * * *$ \\
\hline IM & 0.146 & $-5.094 * * *$ & -0.149 & $-7.868 * * *$ & 43.324 & $82.944 * * *$ & 51.895 & $146.348^{* * *}$ \\
\hline BSIZE & $-2.163^{* *}$ & $-13.294 * * *$ & $-3.249 * * *$ & $-10.911^{* * *}$ & $79.462 * * *$ & $163.247 * * *$ & $61.414^{* *}$ & $252.343^{* * *} *$ \\
\hline SBSZ & $-2.042^{*}$ & $-10.484^{* * *}$ & $-2.186^{* *}$ & $-9.430^{* * *}$ & $36.645^{* *}$ & $86.749^{* * *}$ & 27.422 & $101.967^{* * *}$ \\
\hline
\end{tabular}

Note $\Delta$ represents the first differences

$* * *, * *$ and $*$ indicate statistical significance at the $1 \%, 5 \%$ and $10 \%$ level, respectively

Acknowledgment We acknowledge the Deanship of Scientific Research at Imam Mohammad Ibn Saud Islamic University, Saudi Arabia, for financing this project under grant number (20-13-11-002). Special thanks should be given to Dr. Hiba Hammedi for the English language proofreading.

Funding Imam Mohammad Ibn Saud Islamic University, 20-13-11-002.

\section{Declarations}

Conflict of interest We declare that we have no significant competing financial, professional or personal interests that might have influenced the performance or presentation of the work described in this manuscript. The author declares that he has no conflict of interest.

Human and animal rights This article does not contain any studies with human participants or animals performed by the author.

\section{References}

Ahir, H., N. Bloom, and D. Furceri. 2018. The World Uncertainty Index. https://ssrn.com/abstract=32750 33.

Ahlgrim, K.C., and S.P. D'Arcy. 2012. The effect of deflation or high inflation on the insurance industry. Canadian Institute of Actuaries and Society of Actuaries: Casualty Actuarial Society. 
Akhter, W. 2010. Takaful models and global practices. MPRA Paper 40010, University Library of Munich.

Akhter, W., and S.A. Khan. 2017. Determinants of Takāful and conventional insurance demand: A regional analysis. Cogent Economics and Finance 5 (1): 1-18.

Al Mamun, Md, G. Salah Uddin, M.T. Suleman, and S.H. Kang. 2020. Geopolitical risk, uncertainty and Bitcoin investment. Physica A. https://doi.org/10.1016/j.physa.2019.123107.

Alhassan, A.L., and M.A.A. Boakye. 2020. Board characteristics and life insurance efficiency in South Africa. Pacific Accounting Review 32 (2): 217-237.

Ali, M. 2018. Determinants and consequences of board size: Conditional indirect effects. Corporate Governance 18 (1): 165-184.

Al-Thaqeb, S.A., and A.G. Algharabali. 2019. Economic policy uncertainty: A literature review. The Journal of Economic Asymmetries 20: 2-28.

Antonakakis, N., R. Gupta, C. Kollias, and S. Papadamou. 2017. Geopolitical risks and the oil-stock nexus over 1899-2016. Finance Research Letters 23: 165-173.

Ashraf, B.N., and Y. Shen. 2019. Economic policy uncertainty and banks' loan pricing. Journal of Financial Stability 44:

Asteriou, D., K. Pilbeam, and C.E. Pratiwi. 2020. Public debt and economic growth: Panel data evidence for Asian countries. Journal of Economics and Finance. https://doi.org/10.1007/ s12197-020-09515-7.

Baek, K., and X. Qian. 2011. An analysis on political risks and the flow of foreign direct investment in developing and industrialized economies. Economics, Management and Financial Markets 6 (4): 60.

Baker, S.R., N. Bloom, and S.J. Davis. 2020. World Uncertainty Index for Saudi Arabia [WUISAU]. Retrieved from FRED, Federal Reserve Bank of St. Louis. https://fred.stlouisfed.org/series/WUISAU, March 13, 2020.

Baker, S.R., N. Bloom, and J. Davis. 2016. Measuring economic policy uncertainty. The Quarterly Journal of Economics 131 (4): 1593-1636.

Balbàs, A., B. Balbàs, R. Balbàs, and A. Heras. 2015. Optimal reinsurance under risk and uncertainty. Insurance 60: 61-74.

Balcilar, M., R. Gupta, and C. Jooste. 2014. The role of economic policy uncertainty in forecasting US inflation using a VARFIMA model. Working Paper No. 2014-60.

Balcilar, M., R. Gupta, and C. Pierdzioch. 2016. Does uncertainty move the gold price? New evidence from a nonparametric causality-in-quantiles test. Resources Policy 49: 74-80.

Balcilar, M., R. Gupta, C.C. Lee, and G. Olasehinde-Williams. 2020. Insurance and economic policy uncertainty. Research in International Business and Finance 50:

Balcilar, M., R. Gupta, C. Pierdzioch, and M.E. Wohar. 2018. Terror attacks and stock-market fluctuations: Evidence based on a nonparametric causality-in-quantiles test for the G7 countries. The European Journal of Finance 24 (4): 333-346.

Baltagi, B.H., Q. Feng, and C. Kao. 2012. A Lagrange multiplier test for cross-sectional dependence in a fixed effects panel data model. Journal of Econometrics 170 (1): 164-177.

Batuo, M., K. Mlambo, and S. Asongu. 2018. Linkages between financial development, financial instability, financial liberalisation and economic growth in Africa. Research in International Business and Finance 45: 168-179.

Bernal, O., J.Y. Gnabo, and G. Guilmin. 2016. Economic policy uncertainty and risk spillovers in the Eurozone. Journal of International Money and Finance 65: 24-45.

Biener, C., A. Landmann, and M.I. Santana. 2019. Contract nonperformance risk and uncertainty in insurance markets. Journal of Public Economics 175: 65-83.

Bildirici, M.E., and F. Kayıkçı. 2013. Effects of oil production on economic growth in Eurasian countries: Panel ARDL approach. Energy 49 (1): 156-161.

Bloom, N. 2009. The impact of uncertainty shocks. Econometrica, Econometric Society 77 (3): $623-685$.

Bohnert, A., N. Gatzert, and A. Kolb. 2016. Assessing inflation risk in non-life insurance. Insurance 66: 86-96.

Boubakri, N. 2011. Corporate governance and issues from the insurance industry. The Journal of Risk and Insurance 78 (3): 501-518.

Breusch, T.S., and A. Pagan. 1980. The Lagrange multiplier test and its applications to model specification in econometrics. Review of Economic Studies 47 (1): 239-253.

Caldara, D., and M. Iacoviello. 2018. Measuring geopolitical risk. International Finance Discussion Papers No. 1222. Available at: https://doi.org/10.17016/IFDP.2018.1222. 
Chudik, A., and M.H. Pesaran. 2015. Common correlated effects estimation of heterogeneous dynamic panel data models with weakly exogenous regressors. Journal of Econometrics 188: 393-420.

Dash, S., R.P. Pradhan, R.P. Maradana, K. Gaurav, D.B. Zaki, and M. Jayakumar. 2018. Insurance market penetration and economic growth in Eurozone countries: Time series evidence on causality. Future Business Journal 4 (1): 50-67.

Demir, E., and O. Ersan. 2017. Economic policy uncertainty and cash holdings: Evidence from BRIC countries. Emerging Markets Review 33: 189-200.

Eling, M., and S.D. Marek. 2013. Corporate governance and risk taking: Evidence from the UK and German insurance markets. The Journal of Risk and Insurance 81 (3): 653-682.

Fang, L., H. Yu, and L. Li. 2017. The effect of economic policy uncertainty on the long-term correlation between U.S. stock and bond markets. Economic Modelling 66: 139-145.

Gaganis, C., I. Hasan, and F. Pasiouras. 2020. Cross-country evidence on the relationship between regulations and the development of the life insurance sector. Economic Modelling. https://doi.org/10. 1016/j.econmod.2019.10.024.

Gupta, R., A. Lahiani, C.C. Lee, and C.C. Lee. 2019. Asymmetric dynamics of insurance premium: the impacts of output and economic policy uncertainty. Empirical Economics 57: 1959-1978.

Haiss, P.R., and K. Sümegi. 2008. The relationship of insurance and economic growth: A theoretical and empirical analysis emprica. Journal of Applied Economics and Economic Policy 35 (4): 405-431.

Halicioglu, F. 2007. Residential electricity demand dynamics in Turkey. Energy Economics 29: 199-210.

Han, N.W., and M.W. Hung. 2017. Optimal consumption, portfolio, and life insurance policies under interest rate and inflation risks. Insurance 73: 54-67.

Hassan, M.K., F. Miglietta, P.A. Altrinieri, and J. Floreani. 2018. The effects of Shariah board composition on Islamic equity indices' performance. Business Ethics 27: 248-259.

Haug, A.A. 2002. Temporal aggregation and the power of cointegration tests: A Monte Carlo study. Oxford Bulletin of Economics and Statistics 64 (4): 399-412.

Hemrit, W. 2020. Determinants driving Takaful and cooperative insurance financial performance in Saudi Arabia. Journal of Accounting and Organizational Change 16 (1): 123-143.

Hemrit, W., and N. Benlagha. 2019. Asymmetric impacts of insurance premiums on the non-oil GDP: Some new empirical evidence. Applied Economics 52 (12): 1363-1376.

Im, K.S., M.H. Pesaran, and Y. Shin. 2003. Testing for unit roots in heterogeneous panels. Journal of Econometrics 115: 53-74.

International Monetary Fund. 2019. 2019 Article IV consultation. Press release and staff report. IMF Country Report No. 19/290.

Islamic Financial Services Board. 2019. Islamic financial services industry. Stability report, 2019.

Jensen, M.C., and W.H. Meckling. 1976. Theory of the firm: Managerial behavior, agency costs and ownership structure. Journal of Financial Economics 3 (4): 305-360.

Kader, H.A., M. Adams, P. Hardwick, and W.J. Kwon. 2014. Cost efficiency and board composition under different takaful insurance business models. International Review of Financial Analysis 32: $60-70$.

Kao, C. 1999. Spurious regression and residual-based tests for cointegration in panel data. Journal of Econometrics 90 (1): 1-44.

Karbhari, Y., I. Muye, A.F.S. Hassan, and M. Elnahass. 2018. Governance mechanisms and efficiency: Evidence from an alternative insurance (Takaful) market. Journal of International Financial Markets, Institutions and Money 56: 71-92.

Karnizova, L., and J. Li. 2014. Economic policy uncertainty, financial markets and probability of US recessions. Economics Letters 125 (2): 261-265.

Khoo, J., and A. Cheung. 2020. Does geopolitical uncertainty affect corporate financing? Evidence from MIDAS regression. Global Finance Journal. https://doi.org/10.1016/j.gfj.2020.100519.

Kwak, M., and B.H. Lim. 2014. Optimal portfolio selection with life insurance under inflation risk. Journal of Banking \& Finance 46: 59-71.

Kwon, W.J. 2007. Islamic principles and takaful insurance: Re-evaluation. Journal of Insurance Regulation 18: 109-132.

Lambalk, S., and F.J. De Graaf. 2017. Explaining the relationship between firm performance and corporate governance of Dutch non-life insurance companies: Dutch mutual and commercial companies compared. Journal of Sustainable Finance and Investment 7 (2): 197-231.

Lee, C.C., and C.C. Lee. 2020. Insurance activity, real output, and geopolitical risk: Fresh evidence from BRICS. Economic Modelling 92: 207-215. 
Lee, C.C., C.C. Lee, and S.Y. Xiao. 2020. Policy-related risk and corporate financing behavior: Evidence from China's listed companies. Economic Modelling 94: 539-547.

Lee, C.C., C.H. Chang, M. Arouri, and C.C. Lee. 2016. Economic growth and insurance development: The role of institutional environments. Economic Modelling 59: 361-369.

Levin, A., C.F. Lin, and C.S.J. Chu. 2002. Unit root tests in panel data: asymptotic and finite-sample properties. Journal of Econometrics 108: 1-24.

Liu, G.C., C. Lee, and C.C. Lee. 2016. The nexus between insurance activity and economic growth: A bootstrap rolling window approach. International Review of Economics and Finance 43: 299-319.

MacMinn, R., Y. Ren, and L.M. Han. 2012. Directors and officers insurance, and corporate governance. Journal of Insurance 35 (2): 159-179.

Mensi, W., J. Shahzad, S.M. Hammoudeh, and K.H. Al-Yahyaee. 2017. Asymmetric impacts of public and private investments on the non-oil GDP of Saudi Arabia. International Economics 156: 15-30.

Nagar, V., J. Schoenfeld, and L. Wellman. 2018. The effect of economic policy uncertainty on investor information asymmetry and management disclosures. Journal of Accounting and Economics 67 (1): $36-57$.

Najjar, N. 2012. The impact of corporate governance on the insurance firm's performance in Bahrain. International Journal of Learning and Development 2 (2): 1-17.

Olasehinde-Williams, G.O., and M. Balcilar. 2020. The effect of geopolitical risks on insurance premiums. Journal of Public Affairs 25:

Pedroni, P. 2004. Panel cointegration: Asymptotic and finite sample properties of pooled time series tests with an application to the PPP hypothesis. Department of Economics Working Paper No 2004-15, Williams College.

Peleckienė, V., K. Peleckis, G. Dudzevičiūtè, and K.K. Peleckis. 2019. The relationship between insurance and economic growth: evidence from the European Union countries. Economic ResearchEkonomska Istraživanja 32 (1): 1-17.

Pesaran, M.H. 2004. General diagnostic tests for cross section dependence in panels. IZA DP No 1240.

Pesaran, M.H. 2007. A simple panel unit root test in the presence of cross-section dependence. Journal of Applied Econometrics 22 (2): 265-312.

Pesaran, M.H., Y. Shin, and R.P. Smith. 1999. Pooled mean group estimation of dynamic heterogeneous panels. Journal of the American Statistical Association 94 (446): 621-634.

Pesaran, M.H., and Y. Shin. 1999. An autoregressive distributed lag modelling approach to cointegration analysis. In Econometrics and economic theory in the 20th century: The Ragnar Frisch Centennial Symposium, ed. S. Strom. Cambridge University Press.

Phillips, P.C.B., and D. Sul. 2003. Dynamic panel estimation and homogeneity testing under cross section dependence. The econometrics journal 6 (1): 217-259.

Pradhan, R.P., M.B. Arvin, M. Nair, J.H. Hall, and A. Gupta. 2017. Is there a link between economic growth and insurance and banking sector activities in the G-20 countries? Review of Financial Economics 33: 12-28.

Raheja, C.G. 2005. Determinants of board size and composition: A theory of corporate boards. Journal of Financial and Quantitative Analysis 40 (2): 283-306.

Redzuan, H., Z.A. Rahman, S. Sakinah, and S.H. Aidid. 2009. Economic determinants of family Takaful consumption: Evidence from Malaysia. International Review of Business Research Papers 5 (5): $193-211$.

Robinson, J. 1952. The generalization of the general theory. The rate of interest and other essays. London: MacMillan.

Rothschild, M., and J.E. Stiglitz. 1976. Equilibrium in competitive insurance markets: An essay on the economics of imperfect information. Quarterly Journal of Economics 90: 630-649.

Safieddine, A. 2009. Islamic financial institutions and corporate governance: New insights for agency theory. Corporate Governance: An International Review 17 (2): 142-158.

Saudi Arabian Monetary Authority. 2018. SAMA issues the Saudi insurance market report for 2018. SAMA website.

Shahbaz, M., J. Shahzad, S. Alam, and N. Apergis. 2018. Globalisation, economic growth and energy consumption in the BRICS region: The importance of asymmetries. The Journal of International Trade and Economic Development 27 (8): 985-1009.

Shahbaz, M., Q.M.A. Hye, A. Tiwari, and N.C. Leitão. 2013. Economic growth, energy consumption, financial development, international trade and $\mathrm{CO} 2$ emissions in Indonesia. Renewable and Sustainable Energy Reviews 25: 109-121.

Shleifer, A., and R.W. Vishny. 1997. A survey of corporate governance. Journal of Finance 52: 737-783. 
Singh, S., N. Tabassum, T.K. Darwish, and G. Batsakis. 2018. Corporate governance and Tobin's Q as a measure of organizational performance. British Journal of Management 29 (1): 171-190.

Su, C.W., K. Khan, R. Tao, and M. Nicoleta-Claudia. 2019. Does geopolitical risk strengthen or depress oil prices and financial liquidity? Evidence from Saudi Arabia. Energy 187: 1-13.

Su, C.W., K. Khan, R. Tao, and M. Umar. 2020. A review of resource curse burden on inflation in Venezuela. Energy 204:

Ward, D., and R. Zurbruegg. 2002. Law, politics and life insurance consumption in Asia. The Geneva Papers on Risk and Insurance-Issues and Practice. 27 (3): 395-412.

Westerlund, J., and D. Edgerton. 2007. A panel bootstrap cointegration test. Economics Letters 97 (3): $185-190$.

Xu, Z. 2020. Economic policy uncertainty, cost of capital, and corporate innovation. Journal of Banking \& Finance 111:

Publisher's Note Springer Nature remains neutral with regard to jurisdictional claims in published maps and institutional affiliations.

\section{About the author}

Wael Hemrit Ph.D. is currently an Associate Professor in the Department of Insurance and Risk Management, College of Economics and Administrative Sciences at Imam Mohammad Ibn Saud Islamic University. Broadly, his methodological research focuses on financial economics, risk disclosure and management, renewable energy, uncertainty and insurance. Dr Wael currently works in the field economics and finance and has published a number of papers in various journals, including Asia-Pacific Financial Markets, Journal of Risk Finance, and Applied Economics. 